Historic, Archive Document

Do not assume content reflects current scientific knowledge, policies, or practices 



\section{EDWARDS \&}

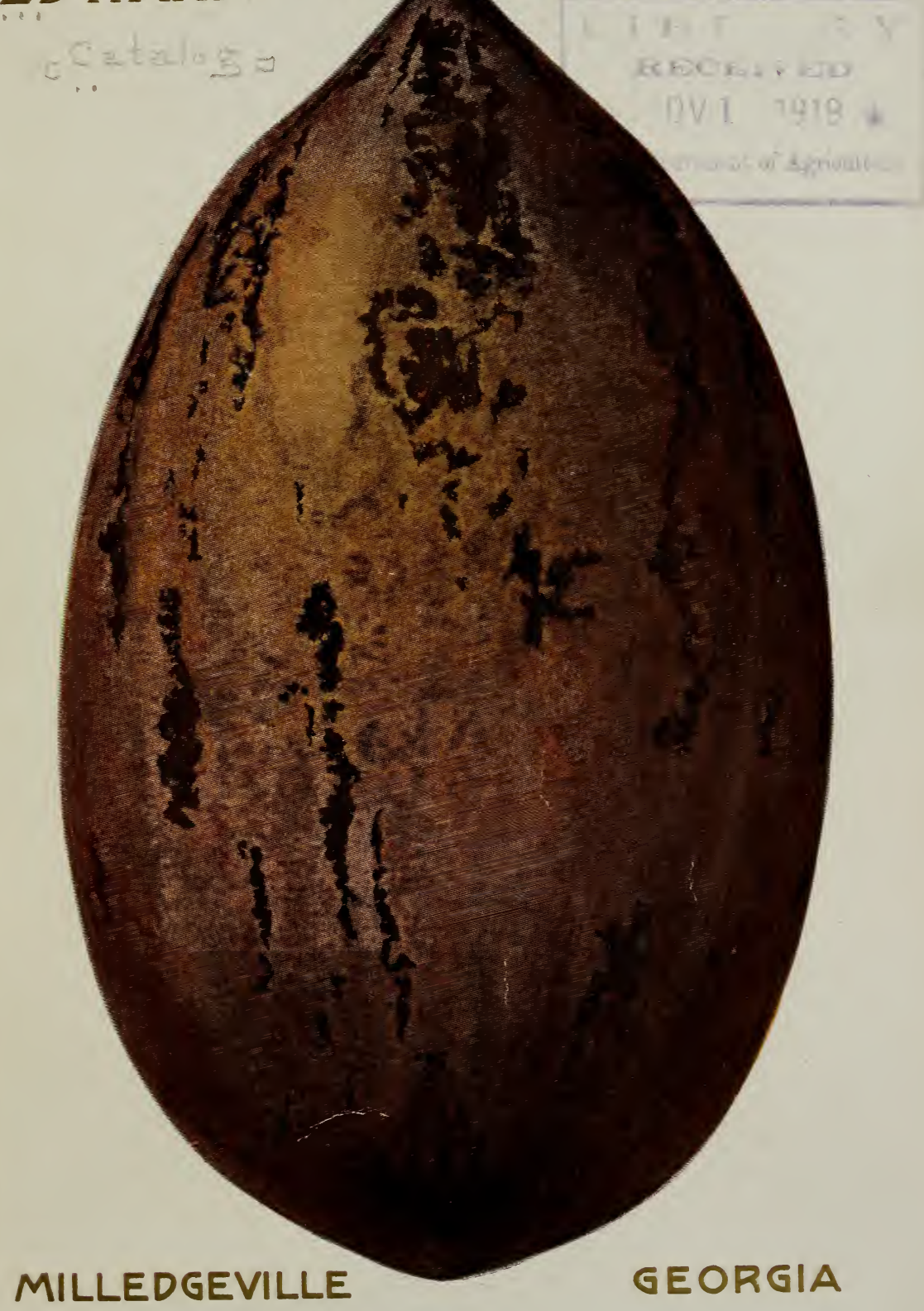





\section{EDWARDS \& PATTERSON MILLEDGEVILLE :: GEORGIA}

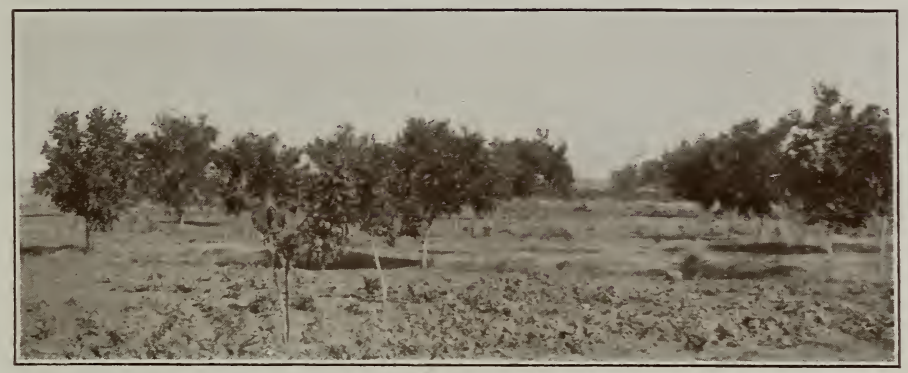

A VIEW IN OUR YOUNG PECAN ORCHARD

\section{A REQUEST.}

Please do not destroy this catalogue. If you are not, at present, interested in Pecan Culture, you may be soon, and we will thank you to either keep this little booklet for future reference, or hand it to someone who, perhaps, is interested Now.

$$
\begin{gathered}
\text { Respectfully, } \\
\text { EDWARDS \& PATTERSON. }
\end{gathered}
$$




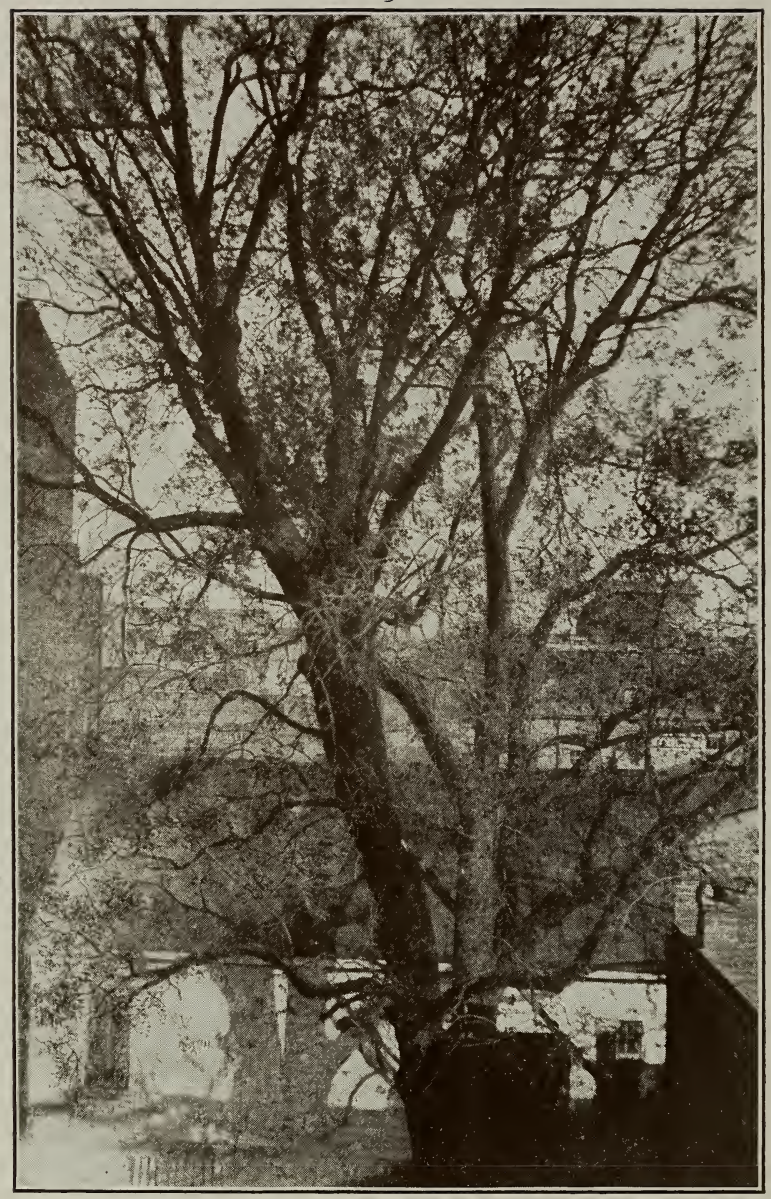

A PECAN TREE IN THE MIDDLE OF A BUSINESS BLOCK AT MILLEDGEVILLE, GA, THE OLDEST INHABITANT CANNOT REMEMBER WHEN THIS TREE WAS PLANTED. IT IS SAID TO BE ABOUT 100 YEARS OLD. THE OWNER CARRIES A $\$ 300.00$ FIRE INSURANCE POLICY ON THIS TREE

ON ACCOUNT OF ITS BEING SURROUNDED BY BUSINESS BUILDINGS, WE COULD ONLY GET A PORTION OF IT IN THE PICTURE 


\section{E D W A R D S \& P A T T E R S O N}

\section{INTRODUCTORY}

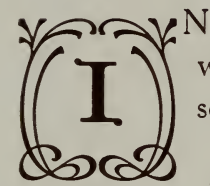

pecan tree.

presenting this catalogue for your consideration we wish to state that we are exclusive Pecan Nurserymen.

We devote our whole time and attention to the We have nothing else for sale.

We believe that we have as fine land as can be found in the pecan belt for the growth of nursery stock. We are located in what might be termed the middle section of the pecan belt. In the North the winters are so severe that pecan nursery stock can not be successfully grown. In the extreme South the winters are so mild that the young tree never becomes thoroughly dormani, and is more subject to winter injury.

In this locality our winters are cold enough to cause the young trees to become dormant, and warm enough to keep them in a good healthy condition throughout the winter season.

We believe that pecan trees grown under these conditions will give quick and profitable results.

We do not claim to be the only people in the business who are putting first-class trees on the market.

We do not claim to grow more trees than anyone else.

We do not claim to sell trees for less than anyone else.

Nor do we claim that our trees will produce nuts as large as the one you see pictured on the front and back cover of this catalogue.

We do claim, however, that when a tree leaves our nursery it is as near perfect as is possible for good land and experienced pecan nurserymen to make it. 


\section{E D W A R D S \& $\mathrm{P}$ A $T$ T $T$ E R $R$ O O N}

Our buds and scions are all taken from bearing trees.

Our trees are all either budded or grafted; most of them are budded. We offer no seedlings at any price.

Our head nurserymen are men of wide experience in pecan culture, and their services, together with our own personal supervision, put us in a position to furnish trees SUPERIOR to some and INFERIOR to none.

To those who have favored us in the past we extend our thanks, and trust that we may be favored with more orders. We believe that we can serve you even better than heretofore, for we are sparing neither time nor expense in improving our facilities. From those who have never had any dealings with us, we would appreciate a trial order, no matter how small. We exercise just as much care in filling an order for five trees as we do in filling an order for five thousand.

We believe we can please you in price, quality and quantity. Sincerely,

Milledgeville, Ga.

EDWARDS \& PATTERSON.

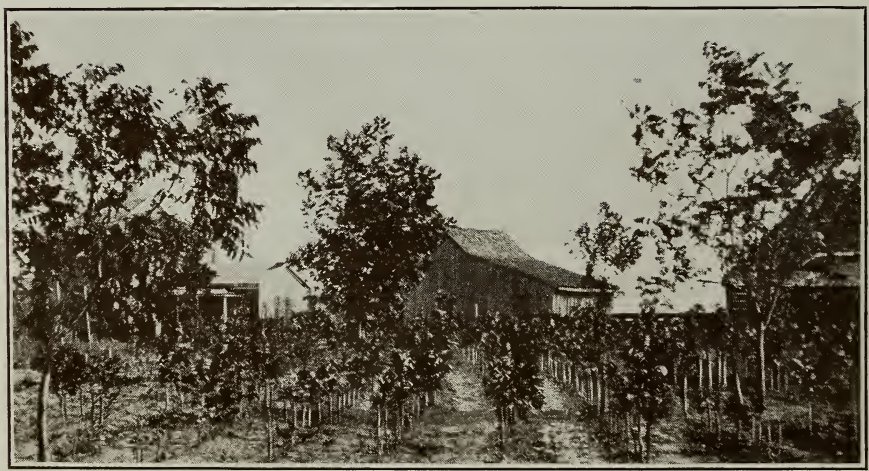

A BLOCK OF YOUNG NURSERY STOCK 


\section{IMPORTANT}

\section{Read Carefully}

Shipping SeAson.-November 20th to March 1st. We do not dig trees until the leaves have fallen and the tree has become thoroughly dormant.

SHIPPING ADDRESS.-In sending orders, purchaser should be very careful to write name and shipping address plainly, and give the number and size of each variety of trees wanted, so that there will be no mistake made in shipping.

Substitution.-We never substitute unless authorized to do so by the purchaser.

TERMS.-Cash with order, or satisfactory reference, during shipping season. On orders booked in advance, a deposit of 25 per cent is required. Balance payable when trees are ordered shipped.

Remittances should be made by P. O. money order, registered letter or bank draft, payable to Edwards \& Patterson.

Transportation.-All goods f. o. b. Milledgeville, Ga., or State Farm, Ga. The same rates apply from both points, either freight or express.

DELIVERY.-We do not guarantee safe delivery of the trees. After we have delivered them, in good condition, to the express or railroad companies our responsibility ceases. Any claims for shortage, damage or delay in transit must be made upon the transportation companies. When so requested we will take pleasure in assisting our customers to trace delayed shipments. 


\section{E D W A R D S \& P A T T E R S O N}

Fumigation.-Before being packed our trees are scientifically fumigated, as required by the Georgia State Board of Entomology.

FREE FROM DISEASE.-Our nursery is free from disease. It is annually inspected by the State Entomologist, and his certificate accompanies every shipment that we make.

PACKING.-We exercise the greatest care in labeling and packing trees, for which we make no extra charge.

Our GuaranteE.-We guarantee all trees sent out to be strictly first-class in every respect, free from disease, true to name, properly packed, and shipped according to instructions. Our liability under this guarantee is limited to either refunding the purchase price or replacing with purchaser's choice, from our list.

Personal Inspection.-Every tree is rigidly inspected by a member of our firm before being packed and shipped.

Claims.-Mistakes are made by everyone. We are not immune, and if, by chance, we should make an error, we shall be pleased to make satisfactory correction upon being

A PACKAGE READY FOR SHIPMENT. TREES PACKED IN THIS MANNER ALWAYS ARRIVE IN GOOD CONDITION notified. Claims should be made immediately after the goods are received.

CARE OF TREes.-When your trees arrive, unpack them at once, "heel" them well in a damp, cool 


\section{I L L E D G E V I L L E, G E O R G I A}

place and let them stay until you are ready to plant them. Dampen the roots when you heel them in. It is best, however, to have your ground ready and the holes dug, ready to receive the trees upon arrival. Under no circumstances should you allow the roots to be exposed to the wind and sunshine. Keep them well protected with wet sacks when you take them to the field to plant.

Time to Plant.-Pecan trees can be planted any time from November 20th to March 10th. December is, perhaps, the best month to plant, although we have had good success in planting as late as the latter part of March.

How to Plant.-We recommend dynamite for digging holes. One-fourth pound of dynamite is suificient to blast a hole about the size and depth of a flour barrel. Let the hole stand open a day or two, to allow the fumes to evaporate, before planting. We send a booklet describing the use of dynamite with every shipment of trees. If not convenient to use dynamite, dig the hole about two feet in diameter and three feet deep. After having trimmed off all bruised or broken roots, place the tree in the hole, about two inches deeper than it stood in the nursery row. This will allow for the dirt to settle well around the roots. When the tree is placed, fill in with good, rich top soil or woods mold. This will be sufficient fertilizer for the first year. Pack dirt WELL around the roots, from bottom to top. After the first year a good fertilizer to use is well-rotted stable manure, ground bone, or any good commercial fertilizer, well dug in. Be careful and do not allow the manure to come in contact with the roots or body of the tree. Put the fertilizer where the roots will grow to it, but not on or among them.

Cultivation.-Keep your trees well cultivated. You must feed and care for your trees, and not leave them to the 


\section{E D W A R D S \& P A T T E R S O N}

mercy of live stock and weeds, if you expect them to give good results. Pecan trees will respond quickly and profitably to good treatment.

Thorough Cultivation.-We advise peas, cotton, melons, potatoes, or any other cultivated crop, between the rows.

Distance to Plant.-40 to 60 feet apart, each way. Number of trees, per acre, at

$$
\begin{aligned}
& 40 \times 40 \text { feet......... } 27 \text { trees } \\
& 50 \times 50 \text { feet. ........ } 17 \text { trees } \\
& 60 \times 60 \text { feet........ } 12 \text { trees }
\end{aligned}
$$

On rich, well-drained bottom land, we recommend planting 50 to 60 feet apart, each way. On thin or hilly land, 40 feet, each way; is about right.

AgE OF BEARING. - With the proper attention, budded or grafted pecan trees will begin bearing at three to five years from time of planting.

The Life of Pecan Trees. - It is not possible to tell just how long a pecan tree will live. We have heard of pecan trees being found that were estimated to be 400 years old. We have pecan trees in Milledgeville, said to be about 100 years old, which are giving increasing crops of nuts each year, and are the most beautiful trees in the city. Some of these trees are pictured in this catalogue. We would not place the average life of a pecan tree at less than 100 years. 


\section{I L L E D G E V I L L E, G E O R G I A}

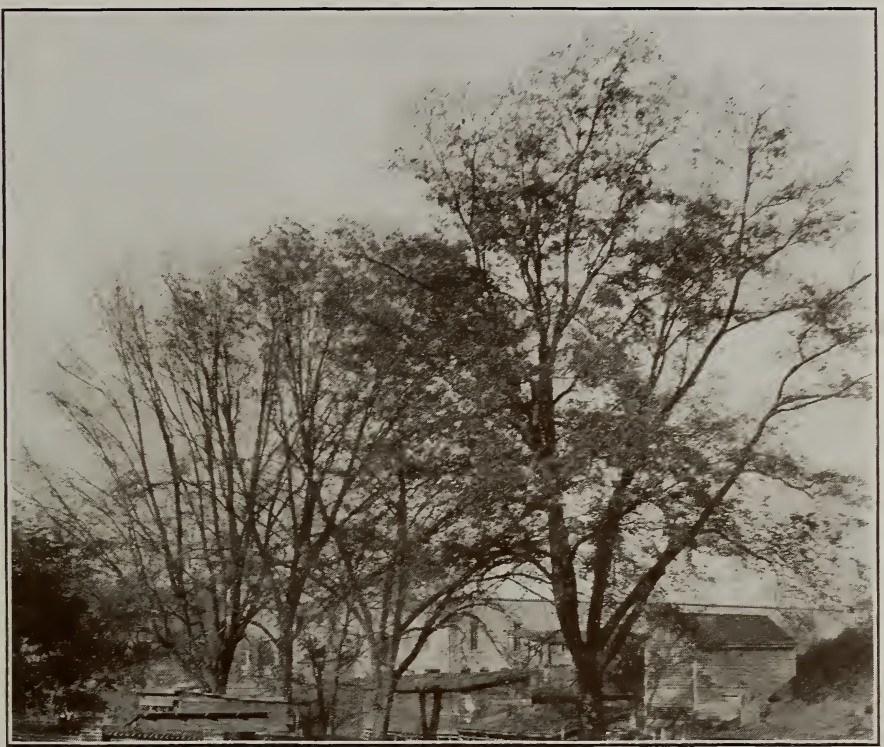

LARGE PECAN TREES AT MILLEDGEVILLE, GA. SOME OF THE OLDEST PECAN TREES IN THE STATE. THESE TREES BEAR BUSHELS OF NUTS EVERY YEAR

\section{VARIETIES}

We have selected the following eight varieties as being among the oldest and best. All large size, thin shell and very prolific.

We are experimenting on other varieties, and as they prove their worth we will propagate them and offer them for sale.

On large orders, for future delivery, we will bud or graft any varieties that the purchaser may desire.

We have no agents. Nor do we act as agents for any other nursery. We offer ONLY our own production.

The nuts pictured on the following pages are natural size. 


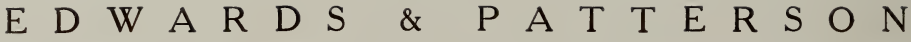

\section{STUART}

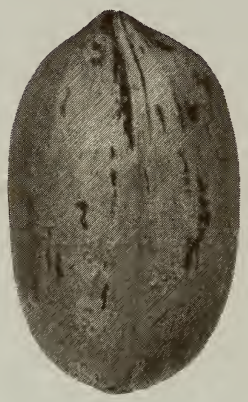

Our Leader. We propagate more of this variety than all others combined.

One of the oldest varieties. Nuts large, shell medium thin. Two nuts placed together in the palm of the hand can be easily crushed. Fills well at both ends, kernel plump, rich and sweet. Tree upright and beautiful. Heavy bearer. Quality the best.

A good variety for Northern planting.

\section{FROTSCHER}

Size large to very large. Shell very thin. A popular variety with nearly all commercial planters. A good filler, a good bearer, and a safe variety to plant.

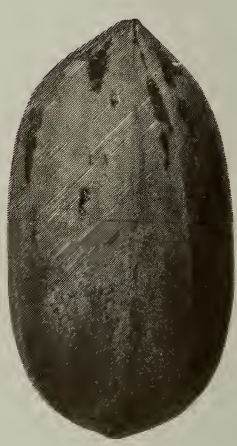




\section{I L L E D G E V I L L E, G E O R G I A}

\section{SCHLEY}

Size large. Shell very thin and brittle. Season early; prolific. A safe variety to plant, and placed, by some planters, at the head of the list.

Quality head of the list.

\section{VANDEMAN}

Size large; 40 to 50 to the pound. Shell thin, pointed. Flavor rich and sweet. A very popular and safe variety to plant.

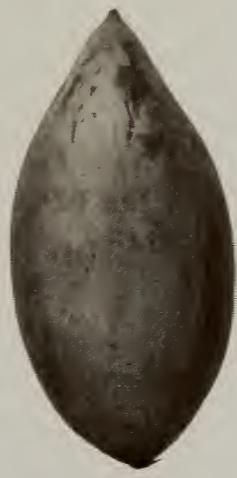




\section{E D W A R D S \& P A T T E R S O N}

\section{SUCCESS}

Size large. Shell thin and cracks well. Kernel full, plump; rich and sweet. A very fine variety, and placed by some planters at the head of the list.

\section{MOBILE}

Size large. Shell thin. Fine flavor. Early and heavy bearer. Tree upright growth.

A safe variety to plant.

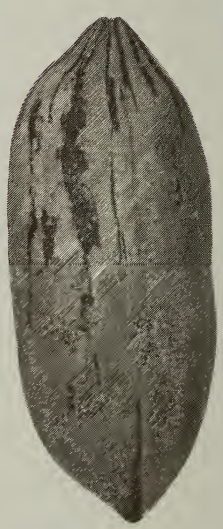




\section{I L L E D G E V I L L E, GE O R G I A}

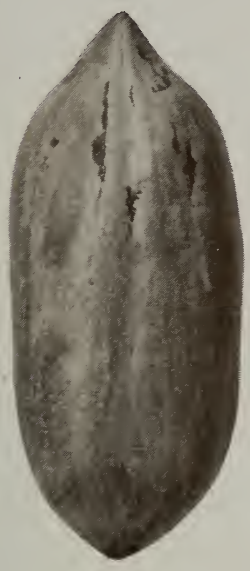

\section{NELSON}

A giant in size. The largest pecan that has ever been propagated. Some of them weighing nearly one ounce.

Shell medium in thickness. A quick grower, early bearer, and very prolific.

\section{MANTURA}

Size large to very large. One of the best of a long list of good ones.

Perhaps the best of all for Northern planting. Succeeds well in North Georgia, Tennessee, Indiana and Virginia.

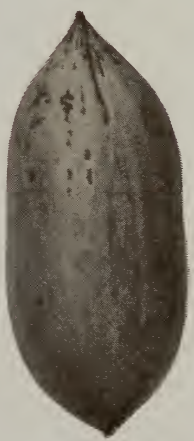




\section{E D W A R D S \& P A T T E R S O N}

\section{WILL PECANS PAY AT 10c PER POUND?}

LET'S SEE. We will take 50 acres of good land, and plant 1,000 trees, 20 trees per acre, of the best varieties. For the first five years we will give these trees the best of attention and cultivation. The first five years it is growth, and not nuts, that we want. The sixth year our trees will give us, say, three pounds of nuts per tree, at $25 \mathrm{c}$ per pound $-75 \mathrm{c}$ per tree, or $\$ 750$ for the thousand trees. The eighth year we should get about five pounds per tree, at $20 \mathrm{c}$ per pound $-\$ 1.00$ per tree, or $\$ 1,000$ for the thousand trees. The tenth year we should be getting ten pounds of nuts per tree, at $15 \mathrm{c}$ per pound $-\$ 1.50$ per tree, or $\$ 1,500$ for the thousand trees. When the trees are fifteen years old we should be getting at least 50 pounds per tree, at $10 \mathrm{c}$ per pound- $\$ 5.00$ per tree, or $\$ 5,000$ for the thousand trees.

Now, bear in mind that for the first ten years we have not lost a single crop of cotton, corn, peas, melons or any other cultivated crop, on account of the trees.

After the first ten years we will turn our pecan orchard into a hay farm, sell the hay for about as much as we would for the same acreage in cotton, and have our nut crop as surplus.

We have estimates made by other nurserymen on file showing more than twice the profits we claim.

Candidly, we do not believe that this generation will see the price of the improved varieties of pecan nuts go below $25 \mathrm{c}$ per pound, but we give the lowest estimate on the yield, and put the price at from $25 \mathrm{c}$ per pound, down to $10 \mathrm{c}$ per pound, just to see if it would pay to grow pecans at $10 \mathrm{c}$ per pound. WE THINK So. Do You? 


\section{I L L E D G E V I L L E, G E O R G I A}

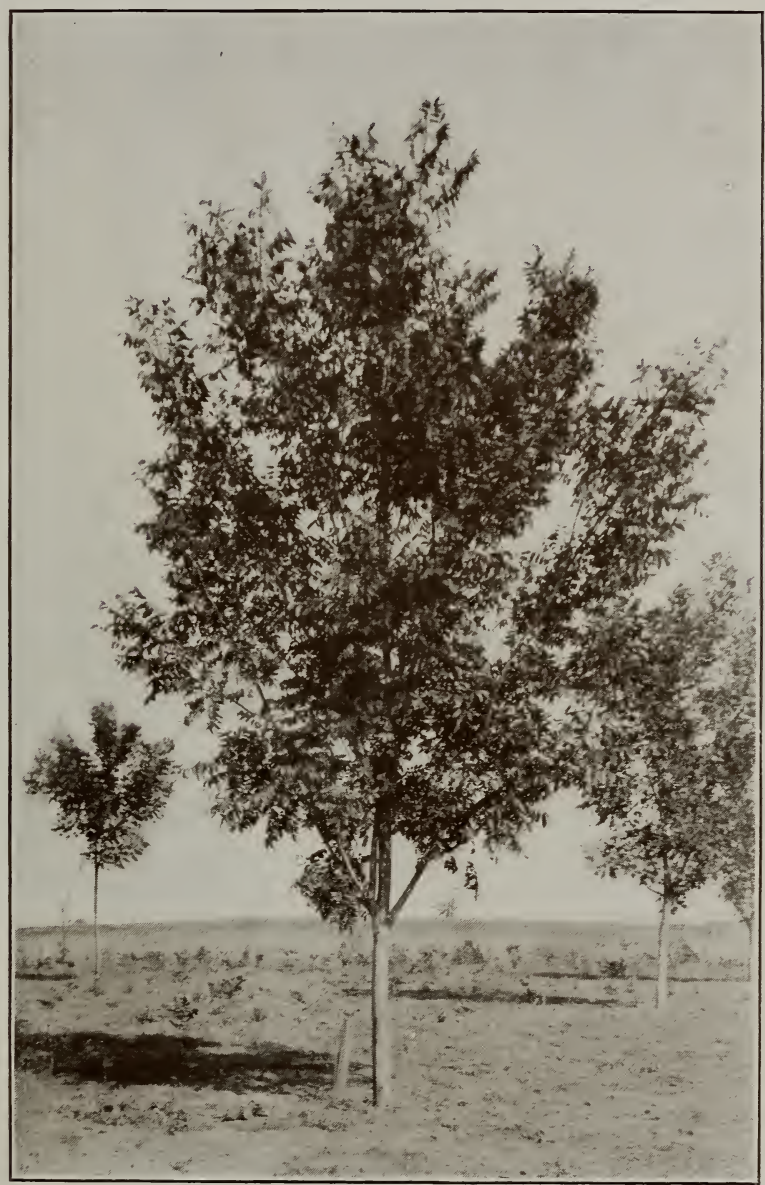

A YOUNG STUART PECAN TREE 


\section{E D W A R D S \& P A T T E R S O N}

\section{WE SAY}

Start a pecan orchard NOw, and add to it each year. Buy our trees, if you will. We will be pleased to sell you, but if you do not buy OUR trees, buy them from some other reliable nursery. BUT, start a pecan orchard, NOw. Give it the same cultivation that you would any other valuable crop, and you will soon have for yourself and loved ones an independent income for the remainder of your lives.

It's better than a Life Insurance Policy, for "You Don'T Have To Die To Get It." 



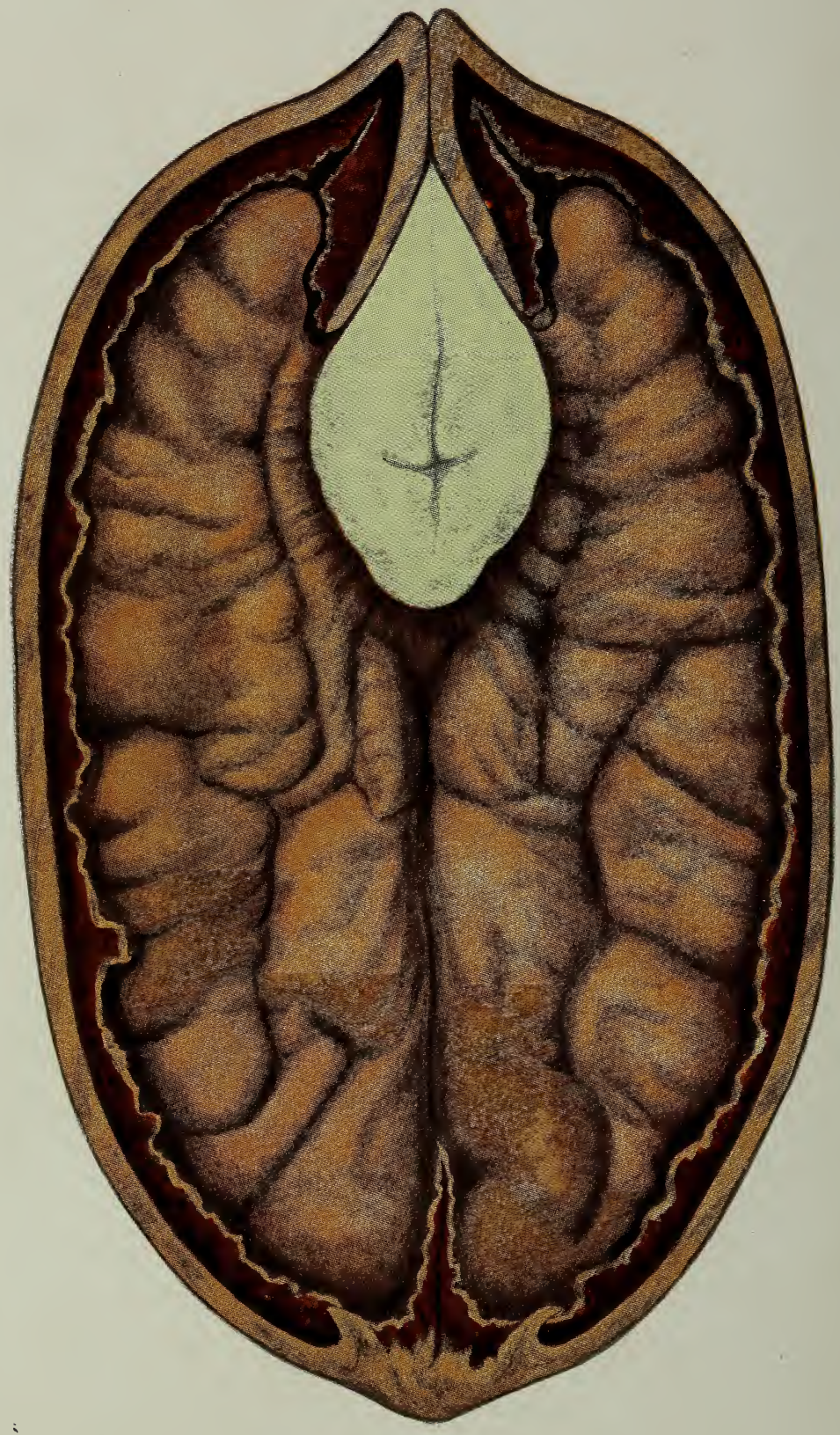

